BMJ Open

Diabetes

Research

\& Care

\title{
Association of diabetes with tooth loss in Hispanic/Latino adults: findings from the Hispanic Community Health Study/ Study of Latinos
}

\author{
Ariel P Greenblatt, ${ }^{1,2}$ Christian R Salazar, ${ }^{3}$ Mary E Northridge, ${ }^{2}$ Robert C Kaplan, ${ }^{3}$ \\ George W Taylor, ${ }^{4}$ Tracy L Finlayson, ${ }^{5}$ Qibin Qi, ${ }^{3}$ Victor Badner ${ }^{1,3}$
}

To cite: Greenblatt AP, Salazar CR, Northridge ME, et al. Association of diabetes with tooth loss in Hispanic/ Latino adults: findings from the Hispanic Community Health Study/Study of Latinos. BMJ Open Diabetes Research and Care 2016;4: e000211. doi:10.1136/ bmjdrc-2016-000211

\section{- Additional material is available. To view please visit the journal (http://dx.doi.org/ 10.1136/bmjdrc-2016- 000211).}

APG and CRS are co-first authors.

Received 11 February 2016 Revised 20 March 2016 Accepted 2 April 2016

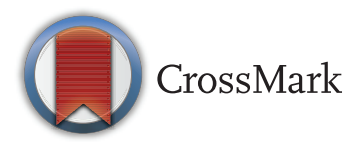

For numbered affiliations see end of article.

Correspondence to Dr Ariel P Greenblatt; ap140@nyu.edu

\section{ABSTRACT}

Objectives: To investigate the association between diabetes mellitus and missing teeth in Hispanic/Latino adults from diverse heritage groups who reside in the USA.

Research design and methods: The Hispanic Community Health Study/Study of Latinos (HCHS/SOL) is a multicenter, population-based study of 1874 years old who underwent a physical and oral examination ( $n=15945)$. Glycemic status was categorized as diabetes, impaired, or normal, based on medication use, and American Diabetes Association criteria for fasting glucose and glycosylated hemoglobin ( $\mathrm{HbA1C}) . \mathrm{HbA} 1 \mathrm{c}<7 \%$ indicated good glycemic control, and $\mathrm{HbA} 1 \mathrm{c}>7 \%$ indicated uncontrolled diabetes. We estimated ORs and 95\% Cls for missing $>9$ teeth and being edentulous (missing all natural teeth), after adjustment for age, income, education, Hispanic background, study site/center, nativity, last dental visit, health insurance, diet quality, cigarette smoking, obesity, periodontitis, and $\mathrm{C}$ reactive protein.

Results: Persons with uncontrolled diabetes had a significant increased likelihood of missing $>9$ teeth and being edentulous as compared with persons with normal glycemic status (adjusted OR=1.92, 95\% Cl 1.44 to 2.55 and adjusted $\mathrm{OR}=1.73,95 \% \mathrm{Cl} 1.22$ to 2.46 , respectively). The association appeared to be stronger at younger ages (18-44 years old; $p$ for interaction $<0.0001)$. However, we found no associations of either impaired glycemia or controlled diabetes with tooth loss in adjusted models.

Conclusions: Dentists should be aware of their Hispanic patients' diabetes status and whether or not they are well controlled, because these may affect tooth loss and impair oral function, which can lead to poor nutrition and complications of diabetes.

\section{INTRODUCTION}

Diabetes is the seventh leading cause of death in the $\mathrm{USA}^{1}$ and is associated with serious oral and systemic health complications, including periodontal disease, which can lead to tooth loss. ${ }^{2}$ Moreover, diabetes is

\section{Key messages}

- Relative to participants with normal glucose tolerance, participants with uncontrolled diabetes had a higher likelihood of both missing nine or more teeth and edentulism.

- No associations were found of either impaired glycemia or controlled diabetes with tooth loss in adjusted models.

- Age, nativity status, income, cigarette smoking, and less healthful eating were associated with higher mean numbers of missing teeth in men and women, and current insurance status was associated with higher mean numbers of missing teeth in women.

especially prevalent among racial/ethnic minorities, including Hispanics, who are currently the largest ethnic minority in the USA, with a population of more than 54 million. Findings from the 2003-2006 National Health and Nutrition Examination Survey (NHANES) indicated the prevalence of diagnosed diabetes for Mexican-Americans was higher than that of non-Hispanic whites for all age groups. ${ }^{4}$ A second NHANES analysis (1988-2012) found nearly half of Hispanics with diabetes had undiagnosed diabetes. ${ }^{5} \mathrm{~A}$ previous analysis from the Hispanic Community Health Study/Study of Latinos (HCHS/SOL) reported that both diabetes and prediabetes are disproportionately high when compared with US national figures and that their prevalence was heterogeneous across Hispanic backgrounds. ${ }^{6}$

Limited but emerging evidence suggests a relationship between diabetes and tooth loss. Tooth loss is typically an indicator of cumulative oral disease burden and access to dental care. A recent analysis using NHANES data found that adults with diabetes aged 50 years and older had higher numbers of missing teeth and were more likely to be edentulous than their counterparts without diabetes. ${ }^{7}$ 
These findings are consistent with those based on data from the Behavioral Risk Factor Surveillance System (BRFSS) where a strong relationship was found between self-reported diabetes and missing teeth in adults aged 18-44 years. ${ }^{8}$ In a second analysis from the BRFSS, adults with diabetes reported a lower quality of life and higher numbers of missing teeth than adults without diabetes. $^{9}$

Missing multiple teeth may lead to inadequate nutritional intake, which is concerning in adults with diabetes, because healthful eating in combination with other factors such as physical activity is important in maintaining glucose control. According to the American Diabetes Association (ADA), nutrition therapy is an integral component of the management of diabetes, because it helps to treat the disease by modifying intake of nutrients and whole foods. The overall goal of nutrition therapy is to create an individualized eating plan for patients in an effort to lower their glucose and blood pressure, and to help reduce their risk for systemic issues, such as coronary heart disease and stroke. ${ }^{10}$ To date, however, no study has examined the association between diabetes and missing teeth in a populationbased sample of US Hispanics.

Hispanics have a disproportionately higher prevalence of diagnosed and undiagnosed diabetes at younger ages compared with other ethnic groups. ${ }^{11}$ Lack of access to health insurance and preventive services in the Hispanic population may accentuate the association between diabetes and poor oral health. ${ }^{12}$ In a cross-sectional sample of community-dwelling impoverished older adults in northern Manhattan, findings were that Hispanic adults and non-Hispanic blacks had a higher prevalence of missing teeth compared with non-Hispanic whites, and that this relationship was strengthened with increasing age and lower levels of educational attainment. ${ }^{13}$ Moreover, a recent report of adults aged 25-44 years found that the prevalence of tooth loss was higher in Hispanics as compared with non-Hispanic whites, indicating that this disparity may also begin in young adulthood. ${ }^{14}$ Hence, we sought to investigate how diabetes relates to cumulative tooth loss in Hispanic populations across age group and by gender.

\section{RESEARCH DESIGN AND METHODS \\ Study population}

The HCHS/SOL is a community-based prospective cohort study of 16415 self-identified Hispanic/Latino persons aged 18-74 years at screening from randomly selected households in four US field centers (Chicago, Illinois; Miami, Florida; Bronx, New York; San Diego, California, USA). The aims of the study were to describe the risk factors, prevalence and incidence of chronic diseases in Hispanics from diverse national/regional backgrounds, of which the largest represented groups were Mexicans, Puerto Ricans, Cubans, Dominicans, Central Americans, and South Americans. Detailed information regarding the sampling design and cohort selection is available elsewhere. ${ }^{15}$ Study visits included medical history, oral examinations, medication inventory, fasting morning blood draw, and demographic and behavioral questionnaires. The analytic sample comprised 15965 ( $\mathrm{n}=15132$ dentate, $\mathrm{n}=833$ edentate) participants with complete data regarding missing teeth and diabetes (97\% of those enrolled). Institutional Review Board approval was obtained at each participating institution, and all participants provided written consent.

\section{Missing teeth}

Trained and calibrated dental examiners ( $\mathrm{n}=13$ across all four study sites) performed a comprehensive oral examination for dental caries and periodontal disease using full-mouth assessments. The examiners determined tooth status by means of visual examination of all teeth present except third molars, ${ }^{16}$ for a total count of 28 teeth. If a tooth was missing, the examiner made a determination, after discussion with the participant, of the reason for the tooth's absence, such as trauma, periodontal disease, caries or orthodontic treatment. In the analyses presented here, we counted teeth that were determined missing due to periodontal disease or caries, but did not count teeth that were missing due to trauma, orthodontic treatment, or other reasons. The specific outcomes for missing teeth used in the analysis were tooth loss $\geq 9$ teeth and total edentulism ${ }^{16}$ (missing 28 teeth, not including wisdom teeth). We defined impaired oral function as missing 9 or more teeth, because adequate oral functioning has been defined as having 20 or more teeth, which equates to missing 8 or fewer teeth (not including third molars). ${ }^{17}$

\section{Diabetes (glycemic status)}

Using the ADA guidelines, glycemic status was used to categorize participants into three groups: diabetes, impaired or normal glucose tolerance. ${ }^{18}$ This definition was derived by taking into account fasting blood glucose levels and glycosylated hemoglobin (HbAlc) percentages from the ADA definition ${ }^{18}$ with the addition of antidiabetes medications.

Individuals with diabetes were defined as those with $\mathrm{HbAlc} \geq 6.5 \%$ or fasting time $>8 \mathrm{~h}$ and fasting glucose $\geq 126 \mathrm{mg} / \mathrm{dL}$ or fasting time $<8 \mathrm{~h}$ and fasting glucose $\geq 200 \mathrm{mg} / \mathrm{dL}$. Individuals with impaired glucose tolerance were defined as those with an HbAlc of 5.7-6.4\% or fasting time $>8 \mathrm{~h}$ and fasting glucose of $100-125 \mathrm{mg} /$ dL. Individuals with normal glucose tolerance were defined as those with HbA1c $<5.7 \%$ and fasting glucose $<100 \mathrm{mg} / \mathrm{dL}$. In addition, among individuals with diabetes, we used $\mathrm{HbAlc}<7 \%$ to indicate controlled diabetes and $\mathrm{HbAlc}>7 \%$ to indicate uncontrolled diabetes. $^{18}$

\section{Covariates}

Bilingual interviewers administered structured questionnaires in English and Spanish at the baseline 
evaluation. ${ }^{15}$ Self-reported nativity status was included as a covariate in the analyses, with US-born defined as birthplace within the 50 states or Washington, DC. Other sociodemographic characteristics included as covariates were age (18-44, 45-64, and 65-74); gender; household income ranging among $<\$ 10000, \$ 10000-$ $\$ 20000, \$ 20001-\$ 40000, \$ 40001-\$ 75000$, and > $\$ 75,000$. Educational attainment was characterized as $<$ high school, high school or equivalent, or $>$ high school education. Current health insurance was categorized as none, private, or Medicaid. Hispanic background (Mexican, Puerto Rican, Cuban, Dominican, Central American, South American, other/mixed), and field center site were also included as covariates.

Behavioral covariates included smoking status (current, former, never), and physical activity level. To ascertain physical activity, we administered a modified WHO Global Physical Activity Questionnaire ${ }^{19}$ to obtain estimates of moderate/vigorous levels of activity from work-related, transportation, and recreational domains. Participants were classified as physically active if they engaged in $\geq 150 \mathrm{~min} /$ week of moderate intensity activity, $\geq 75 \mathrm{~min} /$ week of vigorous intensity activity, or an equivalent combination of activity, as recommended by the 2008 US physical activity guidelines for adults. ${ }^{20}$ We characterized healthy eating using the Alternative Healthy Eating Index-2010 (HEI-2010), which is a score comprised of key dietary requirements, including those for total fruit, total vegetable, and sodium intake. Scores of the HEI-2010 are assigned based on intake levels of dietary requirements. We categorized scores into quintiles, with the highest quintile indicating the healthiest eaters and the lowest quintile containing the least healthy eaters. ${ }^{21}$ Additionally, we adjusted for decayed and filled teeth, using the decayed, missing and filled teeth (DMFT) index, ${ }^{22}$ periodontal disease, using the Centers for Disease Control and Prevention (CDC)/ American Academy of Periodontology (AAP) periodontal disease classification ${ }^{23}$ (disease status characterized as none, mild, moderate, or severe) and $\mathrm{C}$ reactive protein $(\mathrm{CRP})^{24}$ categorized as $<3.0 \mathrm{mg} / \mathrm{dL}$ and $\geq 3.0 \mathrm{mg} / \mathrm{dL}$ according to clinical criteria ${ }^{25}$ to indicate systemic inflammation. Finally, we included information regarding time since the last dental visit $(<1,1-4$, and $>4$ years ago $)^{26}$ and obesity, which was characterized into four groups according to body mass index (BMI) (underweight, normal, overweight, or obese).

\section{Statistical analysis}

In descriptive analyses, we estimated mean numbers of missing teeth in relation to participant characteristics for dentate participants using predicted marginal means and $95 \%$ CIs based on Taylor series linearization from log-linear models. ${ }^{27}$ To examine associations between diabetes and tooth loss, we estimated ORs and 95\% CI of having nine or more missing teeth in dentate participants using logistic regression models adjusting for age, sex, Hispanic background group, study site, nativity status, income, education, last dental visit, current health insurance status, alternative healthy eating index, cigarette smoking, obesity, chronic periodontitis, CRP levels, and percent decay and filled teeth. In secondary analyses, we estimated ORs and 95\% CIs of being edentulous in relation to diabetes status. In exploratory analyses, we stratified models by Hispanic background group to evaluate whether associations between diabetes and missing teeth differed across Hispanic backgrounds (analysis available on request).

In addition, we tested for statistical interaction of diabetes with missing teeth by sex and age group (18-44, 45-65, 65+) in separate logistic regression models using interaction terms (ie, diabetes $\times$ sex; diabetes $\times$ age group) and adjusted for age, Hispanic background group, study site, nativity status, income, education, number of dental visits, current health insurance status, alternative healthy eating index, cigarette smoking, and obesity. A statistically significant interaction between diabetes and age group was not found, so stratified analyses were not shown. All tests were two-sided and statistical significance was defined as $\mathrm{p}<0.05$. All analyses accounted for complex survey design using SUDAAN V.11.0 (RTI, Research Triangle Park, North Carolina, USA).

\section{RESULTS}

\section{Tooth loss by patient characteristics}

Figure 1 presents the distribution of missing teeth in the study population among participants; teeth missing for other reasons than disease were not included (ie, trauma, orthodontics). Note that the figure is unweighted and that the distribution is not normal, with most participants missing either few (1-5) or all of their 28 teeth (mean=5.6, median $=2$ ).

Table 1 presents age-adjusted mean numbers of missing teeth for specified levels of participant

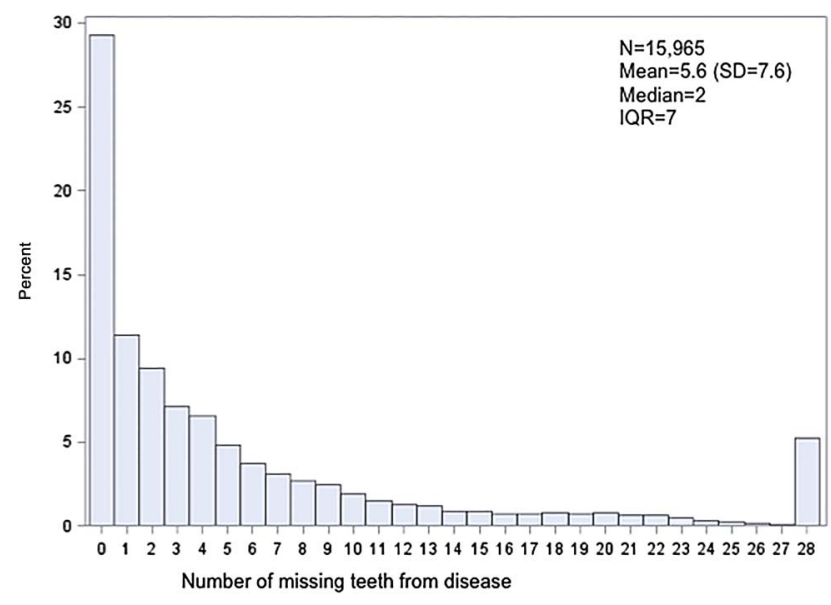

Figure 1 Distribution of missing teeth in Hispanic Community Health Study/Study of Latinos (HCHS/SOL). Note: (1) teeth lost for reasons other than disease (ie, trauma, orthodontic, other) were not counted. (2) Histogram depicting missing teeth from disease was unweighted. 
Table 1 Age-adjusted means $(95 \% \mathrm{Cl})$ of missing teeth across participant characteristics in dentate persons

\begin{tabular}{|c|c|c|c|c|c|c|}
\hline \multirow[b]{2}{*}{$\begin{array}{l}\text { Participant } \\
\text { characteristics }\end{array}$} & \multicolumn{2}{|l|}{ Overall } & \multicolumn{2}{|l|}{ Men } & \multicolumn{2}{|l|}{ Women } \\
\hline & $\begin{array}{l}\text { Unweighted } \\
\mathrm{n}\end{array}$ & $\begin{array}{l}\text { Weighted mean } \\
(95 \% \mathrm{Cl}) \text { number } \\
\text { of missing teeth } \\
\text { from disease }\end{array}$ & $\begin{array}{l}\text { Unweighted } \\
\mathrm{n}\end{array}$ & $\begin{array}{l}\text { Weighted mean } \\
(95 \% \mathrm{Cl}) \text { number } \\
\text { of missing teeth } \\
\text { from disease }\end{array}$ & $\begin{array}{l}\text { Unweighted } \\
\text { n }\end{array}$ & $\begin{array}{l}\text { Weighted mean } \\
(95 \% \mathrm{Cl}) \text { number } \\
\text { of missing teeth } \\
\text { from disease } \\
\end{array}$ \\
\hline \multicolumn{7}{|c|}{ Hispanic background group } \\
\hline Mexican & 6239 & 2.1 (2.0 to 2.2 ) & 2367 & $1.7(1.5$ to 1.9$)$ & 3872 & 2.5 (2.3 to 2.6$)$ \\
\hline Mixed/other & 468 & $3.2(2.2$ to 4.6$)$ & 209 & $2.3(1.7$ to 3.0$)$ & 259 & $4.0(2.4$ to 6.8$)$ \\
\hline Central American & 1616 & 3.7 (3.4 to 3.9$)$ & 646 & $3.0(2.7$ to 3.4$)$ & 970 & 4.2 (3.9 to 4.6$)$ \\
\hline Puerto Rican & 2407 & 3.8 (3.6 to 4.0$)$ & 1016 & 3.4 (3.2 to 3.7 ) & 1391 & 4.1 (3.8 to 4.5$)$ \\
\hline Dominican & 1337 & 4.1 (3.8 to 4.5$)$ & 471 & 3.8 (3.4 to 4.3 ) & 866 & $4.4(4.0$ to 4.8$)$ \\
\hline South American & 990 & 4.2 (3.8 to 4.6$)$ & 410 & 3.9 (3.4 to 4.4$)$ & 580 & 4.5 (4.0 to 5.0$)$ \\
\hline Cuban & 2042 & $4.5(4.2$ to 4.7$)$ & 957 & 4.1 (3.8 to 4.4$)$ & 1085 & 4.9 (4.5 to 5.2$)$ \\
\hline \multicolumn{7}{|l|}{ Nativity status } \\
\hline US born & 2684 & 2.5 (2.2 to 2.7$)$ & 1192 & 2.3 (1.9 to 2.6 ) & 1492 & 2.7 (2.3 to 3.0$)$ \\
\hline $\begin{array}{l}\text { Foreign born } \\
\text { (10+ years in } \\
\text { USA) }\end{array}$ & 8843 & 3.4 (3.2 to 3.6$)$ & 3489 & 3.0 (2.8 to 3.2$)$ & 5354 & 3.7 (3.4 to 4.0$)$ \\
\hline $\begin{array}{l}\text { Foreign born } \\
\text { (<10 years in } \\
\text { USA) }\end{array}$ & 3486 & 3.9 (3.7 to 4.2$)$ & 1363 & 3.5 (3.1 to 3.8$)$ & 2123 & 4.3 (4.0 to 4.7$)$ \\
\hline \multicolumn{7}{|c|}{ Age group (not age-adjusted) } \\
\hline $18-44$ & 6422 & $1.3(1.2$ to 1.4$)$ & 2786 & $1.2(1.1$ to 1.3$)$ & 3636 & 1.5 (1.4 to 1.6$)$ \\
\hline $45-64$ & 7638 & 5.9 (5.7 to 6.3$)$ & 2898 & 5.6 (5.3 to 5.9$)$ & 4740 & 6.2 (5.8 to 6.7$)$ \\
\hline $65-74$ & 1072 & 10.3 (9.7 to 11.0$)$ & 405 & 9.5 (8.6 to 10.5$)$ & 667 & $10.9(10.1$ to 11$)$ \\
\hline \multicolumn{7}{|c|}{ Annual household income } \\
\hline$<\$ 10000$ & 2055 & 4.1 (3.8 to 4.4 ) & 651 & 3.8 (3.4 to 4.2 ) & 1404 & 4.3 (3.9 to 4.7$)$ \\
\hline$\$ 10000-\$ 20000$ & 4495 & 3.7 (3.6 to 4.0$)$ & 1686 & 3.4 (3.1 to 3.7$)$ & 2809 & 4.1 (3.8 to 4.3$)$ \\
\hline$\$ 20001-\$ 40000$ & 4758 & 3.2 (2.9 to 3.4 ) & 2074 & 2.8 (2.6 to 3.1$)$ & 2684 & 3.5 (3.2 to 3.9 ) \\
\hline$\$ 40001-\$ 75000$ & 1924 & 2.5 (2.3 to 2.8$)$ & 942 & $2.4(2.1$ to 2.7$)$ & 982 & 2.7 (2.3 to 3.2$)$ \\
\hline$>\$ 75000$ & 622 & $1.5(1.2$ to 1.9$)$ & 352 & $1.6(1.2$ to 2.0$)$ & 270 & 1.4 (1.1 to 1.8$)$ \\
\hline \multicolumn{7}{|l|}{ Education } \\
\hline$<\mathrm{HS}$ & 5573 & 3.7 (3.5 to 3.9 ) & 2205 & 3.2 (3.0 to 3.5 ) & 3368 & 4.1 (3.8 to 4.4 ) \\
\hline HS or equivalent & 3908 & 3.7 (3.5 to 4.0$)$ & 1721 & 3.3 (3.0 to 3.5 ) & 2187 & 4.2 (3.8 to 4.7$)$ \\
\hline$>\mathrm{HS}$ & 5614 & 2.9 (2.8 to 3.2$)$ & 2150 & 2.7 (2.4 to 2.9$)$ & 3464 & 3.2 (3.0 to 3.5 ) \\
\hline \multicolumn{7}{|l|}{ Current insurance } \\
\hline Medicaid & 7494 & 3.6 (3.3 to 3.8 ) & 3170 & 3.2 (3.0 to 3.5 ) & 4324 & 3.9 (3.6 to 4.1$)$ \\
\hline None & 2824 & 4.1 (3.8 to 4.4 ) & 900 & 3.6 (3.3 to 3.9$)$ & 1924 & 4.5 (4.1 to 4.9$)$ \\
\hline Other & 4679 & 2.7 (2.5 to 2.9$)$ & 1957 & 2.4 (2.2 to 2.6 ) & 2722 & 3.0 (2.7 to 3.2$)$ \\
\hline \multicolumn{7}{|l|}{ Last dental visit } \\
\hline$<1$ year ago & 7688 & 3.4 (3.2 to 3.6 ) & 2748 & 3.0 (2.8 to 3.2$)$ & 4940 & 3.7 (3.4 to 4.0$)$ \\
\hline 1 to $<4$ years ago & 5168 & 3.4 (3.2 to 3.7 ) & 2108 & 3.1 (2.8 to 3.3 ) & 3060 & 3.8 (3.5 to 4.1$)$ \\
\hline $\begin{array}{l}4 \text { or more years } \\
\text { ago }\end{array}$ & 2247 & 3.6 (3.3 to 3.9$)$ & 1224 & $3.1(2.8$ to 3.4$)$ & 1023 & 4.2 (3.8 to 4.7$)$ \\
\hline \multicolumn{7}{|l|}{ Obesity ${ }^{*}$} \\
\hline $\begin{array}{l}\text { Underweight } \\
(\mathrm{BMI}<18.5)\end{array}$ & 118 & 4.3 (3.1 to 5.9$)$ & 47 & $4.4(3.4$ to 5.8$)$ & 71 & $4.1(2.3$ to 7.1$)$ \\
\hline $\begin{array}{l}\text { Normal weight } \\
(\mathrm{BM}=18.5 \text { to }<25)\end{array}$ & 2948 & 3.3 (3.0 to 3.5$)$ & 1207 & 3.4 (3.1 to 3.8$)$ & 1741 & 3.1 (2.8 to 3.4$)$ \\
\hline $\begin{array}{l}\text { Overweight } \\
(\mathrm{BMI}=25 \text { to }<30)\end{array}$ & 5650 & 3.3 (3.1 to 3.5$)$ & 2547 & $2.8(2.6$ to 3.1$)$ & 3103 & 3.7 (3.5 to 4.0$)$ \\
\hline Obese $(\mathrm{BMl}=30+)$ & 6375 & 3.6 (3.4 to 3.8 ) & 2269 & 3.0 (2.8 to 3.3 ) & 4106 & 4.0 (3.7 to 4.3 ) \\
\hline \multicolumn{7}{|l|}{ Cigarette smoking } \\
\hline Never & 9359 & 3.1 (2.9 to 3.3 ) & 2994 & 2.6 (2.4 to 2.8 ) & 6365 & 3.4 (3.2 to 3.7 ) \\
\hline Former & 2954 & 3.3 (3.1 to 3.6$)$ & 1572 & 2.7 (2.5 to 3.0$)$ & 1382 & 4.2 (3.8 to 4.5$)$ \\
\hline Current & 2788 & $4.7(4.4$ to 5.0$)$ & 1503 & $4.4(4.1$ to 4.7$)$ & 1285 & 5.1 (4.6 to 5.6$)$ \\
\hline \multicolumn{7}{|c|}{ Alternative Healthy Eating Index 2010} \\
\hline Lowest fifth† & 2668 & 4.5 (4.2 to 4.9$)$ & 941 & 4.1 (3.7 to 4.6$)$ & 2027 & 4.8 (4.3 to 5.3$)$ \\
\hline Second fifth & 2949 & 4.1 (3.8 to 4.4 ) & 1175 & 4.0 (3.7 to 4.3 ) & 1774 & 4.3 (3.9 to 4.7 ) \\
\hline
\end{tabular}


Table 1 Continued

\begin{tabular}{|c|c|c|c|c|c|c|}
\hline \multirow[b]{2}{*}{$\begin{array}{l}\text { Participant } \\
\text { characteristics }\end{array}$} & \multicolumn{2}{|l|}{ Overall } & \multicolumn{2}{|l|}{ Men } & \multicolumn{2}{|l|}{ Women } \\
\hline & $\begin{array}{l}\text { Unweighted } \\
n\end{array}$ & $\begin{array}{l}\text { Weighted mean } \\
(95 \% \mathrm{Cl}) \text { number } \\
\text { of missing teeth } \\
\text { from disease }\end{array}$ & $\begin{array}{l}\text { Unweighted } \\
\mathrm{n}\end{array}$ & $\begin{array}{l}\text { Weighted mean } \\
(95 \% \mathrm{Cl}) \text { number } \\
\text { of missing teeth } \\
\text { from disease }\end{array}$ & $\begin{array}{l}\text { Unweighted } \\
\mathrm{n}\end{array}$ & $\begin{array}{l}\text { Weighted mean } \\
(95 \% \mathrm{Cl}) \text { number } \\
\text { of missing teeth } \\
\text { from disease }\end{array}$ \\
\hline Third fifth & 2979 & 3.6 (3.4 to 3.8 ) & 1183 & 3.3 (3.0 to 3.6$)$ & 1796 & 3.9 (3.6 to 4.2$)$ \\
\hline Fourth fifth & 3040 & 3.0 (2.8 to 3.2$)$ & 1203 & 2.7 (2.5 to 3.0$)$ & 1837 & 3.3 (3.0 to 3.5$)$ \\
\hline Highest fifth $\ddagger$ & 3047 & 2.2 (2.0 to 2.4$)$ & 1515 & 1.9 (1.7 to 2.1$)$ & 1532 & 2.6 (2.3 to 2.9 ) \\
\hline
\end{tabular}

characteristics in dentate persons, both overall and separately for men and women. Patterns of tooth loss are consistent across categories within participant characteristics for men and women, yet women generally exhibit higher mean missing teeth than men. Associations were evident for nativity status, age group, and annual household income, with higher mean numbers of missing teeth for foreign-born versus US-born, older versus younger, and lower versus higher annual household income participants. Women enrolled in Medicaid have higher mean numbers of missing teeth than those with none or other health insurance, yet this relationship was not found in men, relatively fewer of whom were Medicaid enrollees.

Both overall and for men and women separately, there is a strong gradient of mean missing teeth across smoking status, with never-smokers having 3.1 mean missing teeth and current smokers having 4.7 mean numbers of missing teeth. No consistent trend in the mean number of missing teeth was evident by the participants. This study also elucidated the fact that in this population, compared with persons with normal glucose tolerance, diabetes status (controlled and uncontrolled) defined BMI levels, although underweight participants tended to have the highest numbers of missing teeth. Healthy eating pattern was related to fewer numbers of mean missing teeth. The difference for participants in the healthiest eating index quintile compared with participants in the unhealthiest eating quintile is more than 2 fewer mean number of missing teeth, as people in the unhealthiest quintile (the lowest fifth) have 4.5 mean missing teeth and those in the highest quintile have 2.2 mean numbers of missing teeth.

\section{Associations of diabetes status with tooth loss}

Table 2 presents associations of diabetes and tooth loss in the overall study population and by gender. Overall, individuals with diabetes were significantly more likely to have $>9$ missing teeth than those without diabetes (model 1; adjusted OR=1.40, 95\% CI 1.12 to 1.76). Among persons with diabetes, those with uncontrolled diabetes had significantly higher odds of having $\geq 9$ missing teeth than those without diabetes (model 1; adjusted OR=1.92, 95\% CI 1.44 to 2.55). Similar patterns of these associations were observed in men and in women. However, there were no associations between impaired glycemic status (prediabetes) or controlled diabetes with missing teeth. Additionally, we found that neither duration of diabetes nor level of diabetes control changed our overall findings (see online supplementary table S1).

While adjustment for chronic periodontitis and CRP did not change any of the effect estimates, control for percentage of decayed and filled teeth attenuated all observed associations by an appreciable amount in the overall population (table 2, model 2). These attenuations were more pronounced in women than in men. Sensitivity analyses showed that the percentage of filled teeth rather than percentage of decayed teeth was the driver of these observed attenuations (data not shown). When complete tooth loss (edentulism) was considered as the outcome (table 3), we similarly observed a higher likelihood of being edentulous odds in persons with uncontrolled diabetes as compared with those without diabetes in the fully adjusted model (adjusted OR 1.73; 95\% CI 1.22 to 2.46 ). This association was similar in men and women.

In exploratory analyses, we tested for interaction of diabetes and missing teeth by age (see online supplementary table S2). Overall, we found that the relationship of diabetes with missing teeth was stronger at younger ages ( $p$ for interaction <0.0001; in men: $\mathrm{p}=0.0013$, in women: $\mathrm{p}=0.0462)$. We also tested for interaction by Hispanic heritage groups and found no evidence that the associations varied significantly by Hispanic background (data available on request).

\section{CONCLUSIONS}

\section{Summary of findings}

This analysis represents the first to examine the relationship between diabetes and tooth loss in persons from diverse Hispanic background groups using data from HCHS/SOL. The principal finding of this study is that relative to participants with normal glucose tolerance, participants with uncontrolled diabetes had a higher 
Table 2 Associations of tooth loss with diabetes status stratified by gender

\begin{tabular}{|c|c|c|c|c|c|}
\hline & \multirow{2}{*}{$\begin{array}{l}\text { Unweighted } \\
\mathbf{N}\end{array}$} & \multirow{2}{*}{$\begin{array}{l}\text { Weighted mean } \\
(95 \% \mathrm{Cl}) \text { number } \\
\text { of missing teeth* }\end{array}$} & \multicolumn{3}{|c|}{ ORs $(95 \% \mathrm{Cl})$ for having $9+$ missing teeth } \\
\hline & & & $\mathbf{N}$ cases & Model 1† & Model 2‡ \\
\hline \multicolumn{6}{|l|}{ Overall§ } \\
\hline Normal & 6479 & 3.2 (3.0 to 3.5$)$ & 646 & 1.00 (referent) & 1.00 (referent) \\
\hline Prediabetes & 5842 & 3.4 (3.2 to 3.6$)$ & 1167 & $1.13(0.96$ to 1.34$)$ & $1.06(0.89$ to 1.26$)$ \\
\hline Diabetes & 2792 & 3.6 (3.3 to 3.9$)$ & 820 & 1.40 (1.12 to 1.76$)$ & $1.18(0.94$ to 1.49$)$ \\
\hline Controlled $(\mathrm{HbA} 1 \mathrm{c}<7 \%)$ & 1468 & 3.3 (3.0 to 3.5$)$ & 415 & 1.07 (0.82 to 1.38$)$ & $0.97(0.74$ to 1.28$)$ \\
\hline Uncontrolled (HbA1c $\geq 7 \%)$ & 1324 & 4.0 (3.6 to 4.5$)$ & 405 & 1.92 (1.44 to 2.55$)$ & $1.49(1.11$ to 1.99$)$ \\
\hline Total & 15113 & & 2633 & & \\
\hline \multicolumn{6}{|l|}{ Men } \\
\hline Normal & 2530 & 2.9 (2.6 to 3.2$)$ & 212 & 1.00 (referent) & 1.00 (referent) \\
\hline Prediabetes & 2476 & 3.1 (2.8 to 3.3$)$ & 417 & $1.11(0.85$ to 1.46$)$ & 1.07 (0.81 to 1.42$)$ \\
\hline Diabetes & 1078 & 3.1 (2.8 to 3.4$)$ & 276 & 1.40 (0.97 to 2.00$)$ & 1.33 (0.92 to 1.92$)$ \\
\hline Controlled $(\mathrm{HbA} 1 \mathrm{c}<7 \%)$ & 512 & 2.7 (2.4 to 3.1$)$ & 121 & 0.97 (0.65 to 1.44$)$ & 0.99 (0.66 to 1.49$)$ \\
\hline Uncontrolled (HbA1c $\geq 7 \%)$ & 566 & 3.5 (3.1 to 3.9$)$ & 155 & 1.98 (1.26 to 3.12$)$ & $1.76(1.12$ to 2.78$)$ \\
\hline Total & 6084 & & 905 & & \\
\hline \multicolumn{6}{|l|}{ Women } \\
\hline Normal & 3949 & 3.5 (3.3 to 3.8$)$ & 434 & 1.00 (referent) & 1.00 (referent) \\
\hline Prediabetes & 3366 & 3.8 (3.5 to 4.0$)$ & 750 & $1.13(0.90$ to 1.41$)$ & $1.03(0.82$ to 1.29$)$ \\
\hline Diabetes & 1714 & 4.1 (3.7 to 4.5$)$ & 544 & 1.41 (1.06 to 1.89$)$ & $1.07(0.78$ to 1.45$)$ \\
\hline Controlled $(\mathrm{HbA} 1 \mathrm{c}<7 \%)$ & 956 & 3.7 (3.4 to 4.1$)$ & 294 & $1.14(0.82$ to 1.60$)$ & $0.93(0.64$ to 1.34$)$ \\
\hline Uncontrolled (HbA1c $\geq 7 \%)$ & 758 & 4.5 (3.9 to 5.3$)$ & 250 & 1.87 (1.29 to 2.70$)$ & $1.29(0.89$ to 1.87$)$ \\
\hline Total & 9029 & & 1728 & & \\
\hline
\end{tabular}

*Means adjusted for age.

†Model 1 adjusted for age, Hispanic background, study site/center, nativity status, income, and education, adjusted number of dental visits and current health insurance status, alternative healthy eating index, cigarette smoking, and obesity, chronic periodontitis (CDC/AAP case definition: none, mild, moderate, severe).

$\ddagger$ Model 2 adjusted for age, Hispanic background, study site/center, nativity status, income, and education, adjusted number of dental visits and current health insurance status, alternative healthy eating index, cigarette smoking, and obesity, chronic periodontitis (CDC/AAP case definition: none, mild, moderate, severe), and percentage (\%) of decayed and filled teeth.

§ORs were further adjusted for gender.

HbA1c, glycosylated hemoglobin.

likelihood of both missing nine or more teeth and edentulism. The findings persisted after adjustment for an array of potential confounders including socioeconomic status, number of dental visits and health behaviors. These findings are similar to those from a prospective population-based study in Germany, where uncontrolled diabetes was associated with increased mean periodontal attachment loss and an increased risk of future tooth loss compared with normal glycemic status. ${ }^{28}$ Our finding that uncontrolled diabetes was associated with edentulism is consistent with an analysis of 2003-2004 NHANES data, in which persons with diabetes had a greater likelihood of being edentulous, compared with those without diabetes. ${ }^{7}$

A positive relationship exists between glucose impairment and mean numbers of missing teeth. That is, compared with persons with normal glucose tolerance, persons with impaired glucose tolerance and diabetes had higher mean numbers of missing teeth. ${ }^{7}$ In our study population, age, nativity status, income, cigarette smoking, and less healthful eating were associated with higher mean numbers of missing teeth in men and women, and current insurance status was associated with higher mean numbers of missing teeth in women. A population-based study in Germany reported an overall positive association between type 2 diabetes and number of missing teeth, which was stronger in women than in men. ${ }^{29}$

Elevated CRP levels have been found to be associated with tooth loss and advanced periodontal disease, ${ }^{30}$ yet in our sample, adjustments for CRP did not attenuate the relationships. Since chronic periodontitis and dental caries are leading causes of tooth loss, we adjusted for these conditions in the analyses. Mechanistic studies have found that diabetes leads to an exacerbated inflammatory response in the periodontium, which impairs healing and repair to the related periodontal structures and results in enhanced destruction. Moreover, the relationship between periodontal disease and diabetes is bidirectional. Thus, not only can diabetes enhance periodontal destruction and inhibit repair, but periodontal disease can also contribute to impaired glycemic status. ${ }^{31}{ }^{32}$ To test for this potential pathway between diabetes and periodontal disease, we adjusted for chronic periodontitis in the multivariable models, but the effect estimates were unchanged.

Our finding that the percentage of filled teeth attenuated the associations between impaired glycemic status and tooth loss and edentulism in women suggests a possible treatment effect; that is, women are more likely to 
Table 3 Associations of being edentulous with diabetes stratified by gender

\begin{tabular}{|c|c|c|c|}
\hline & $\begin{array}{l}\text { Unweighted } \\
\mathrm{N}\end{array}$ & $\mathrm{N}$ cases & ORs* $(95 \% \mathrm{Cl})$ for being edentulous \\
\hline \multicolumn{4}{|l|}{ Overall } \\
\hline Normal & 6664 & 185 & 1.00 (referent) \\
\hline Prediabetes & 6177 & 335 & $1.00(0.76$ to 1.32$)$ \\
\hline Diabetes & & & $1.52(1.13$ to 2.03$)$ \\
\hline Controlled (HbA1c<7\%) & 1611 & 143 & $1.3(0.94$ to 1.94$)$ \\
\hline Uncontrolled (HbA1c $\geq 7 \%)$ & 1491 & 167 & 1.73 (1.22 to 2.46$)$ \\
\hline Total & 15943 & 520 & \\
\hline \multicolumn{4}{|l|}{ Men } \\
\hline Normal & 2599 & 69 & 1.00 (referent) \\
\hline Prediabetes & 2614 & 138 & $1.07(0.72$ to 1.61$)$ \\
\hline Diabetes & & & 1.66 (1.03 to 2.68$)$ \\
\hline Controlled (HbA1c<7\%) & 560 & 48 & $1.50(0.81$ to 2.79$)$ \\
\hline Uncontrolled $(\mathrm{HbA} 1 \mathrm{c} \geq 7 \%)$ & 624 & 58 & 1.86 (1.10 to 3.14$)$ \\
\hline Total & 6397 & 402 & \\
\hline \multicolumn{4}{|l|}{ Women } \\
\hline Normal & 4065 & 116 & 1.00 (referent) \\
\hline Prediabetes & 3563 & 197 & $0.93(0.64$ to 1.34$)$ \\
\hline \multicolumn{4}{|l|}{ Diabetes } \\
\hline Controlled $(\mathrm{HbA} 1 \mathrm{c}<7 \%)$ & 1051 & 95 & 1.44 (1.03 to 2.02$)$ \\
\hline Uncontrolled (HbA1c $\geq 7 \%)$ & 867 & 109 & 1.29 (0.86 to 1.92$)$ \\
\hline Total & 9546 & 517 & 1.67 (1.11 to 2.52$)$ \\
\hline
\end{tabular}

${ }^{*}$ ORs adjusted for age, Hispanic background, study site/center, nativity status, income, and education, number of dental visits and current health insurance status, alternative healthy eating index, cigarette smoking, and obesity.

HbA1c, glycosylated hemoglobin.

seek dental care than men, and young women tend to have better dental hygiene habits than young men. ${ }^{33} 34$ In anthropological studies, women have been found to have higher rates of dental caries and tooth $\operatorname{loss}^{35}{ }^{36}$; thus, gender differences in oral health could be due to biological or dietary reasons in addition to a treatment effect.

In our analysis, we aimed to evaluate differences in the relationship between diabetes and missing teeth by Hispanic/Latino heritage groups in HCHS/SOL. A previous report examining the prevalence of cardiovascular disease (CVD) risk factors in HCHS/SOL found significant variations in risk factor prevalence among heterogeneous Hispanic background groups in HCHS/SOL, with a particularly elevated risk for CVD in Puerto Ricans. ${ }^{37}$ In contrast, in our study, we did not find marked differences among Hispanic background groups in mean numbers of missing teeth or edentulism.

Not since the early 1980s when the Hispanic Health and Nutrition Examination Survey (HHANES) aimed to provide a baseline for chronic conditions in Hispanic Americans has a population-based study collected and evaluated data from Hispanic background groups on such a large scale. HHANES was both an informative and comprehensive baseline, but its data collection was limited to Mexican-Americans, Puerto Ricans, and Cuban-Americans. ${ }^{38}$ The HCHS/SOL study population also includes Dominican-Americans, Central and South Americans as well as Mexican-Americans, Puerto Ricans, and Cuban-Americans, which is a major strength of this analysis. Moreover, HCHS/SOL uses a hybrid design, which incorporates probability sampling within preselected heterogeneous locations. Compared with surveillance systems such as the BRFSS that use a self-report definition of diabetes, HCHS/SOL uses the ADA definition of diabetes status involving clinical measures, which allows for careful assessment of glycemic status. ${ }^{18}$ One limitation of this analysis is that it is cross-sectional; hence, whether diabetes preceded the tooth loss, or vice versa, cannot be determined. Another potential limitation is that teeth missing from orthodontic treatment or trauma may also have had underlying dental problems. Finally, we were unable to distinguish between type 1 and type 2 diabetes mellitus in this data set, so we were unable to analyze the data based on type of diabetes.

In conclusion, we found that diabetes is related to tooth loss in Hispanics/Latinos overall, which is a relationship that has not been previously examined in such a large sample size of Hispanics/Latinos. This study also elucidated the fact that in this population, compared with persons with normal glucose tolerance, uncontrolled diabetes was related to higher mean numbers of missing teeth. Moreover, uncontrolled diabetes is a driver for tooth loss $>9$ teeth, which is an indicator of functional dentition. ${ }^{39}$ This analysis suggests that dentists should be aware of their Hispanic ${ }^{7}{ }^{10}$ patients' diabetes status and whether or not they are well controlled, because it could impact tooth loss and impair oral function, which can lead to poor nutrition and chronic complications of diabetes. ${ }^{10}$ 
Author affiliations

${ }^{1}$ Jacobi Medical Center, Bronx, New York, USA

${ }^{2}$ New York University College of Dentistry, New York, New York, USA

${ }^{3}$ Albert Einstein College of Medicine, Bronx, New York, USA

${ }^{4}$ University of California San Francisco School of Dentistry, San Francisco, California, USA

${ }^{5}$ Graduate School of Public Health, San Diego State University, San Diego, California, USA

Acknowledgements The authors thank the staff and participants of HCHS/ SOL for their important contributions. A complete list of staff and investigators has been provided by Sorlie et $a^{27}$ and is also available on the study website http://www.cscc.unc.edu/hchs/.

Contributors APG conceptualized the study and wrote the manuscript; CRS conducted the data analysis and aided in writing the paper; MEN contributed to writing, editing, and revising the manuscript; RCK reviewed and edited the manuscript; GWT contributed to the data analysis and discussion; TLF reviewed and edited the manuscript; $Q Q$. reviewed the manuscript; and VB collected data and reviewed the manuscript.

Funding The Hispanic Community Health Study/Study of Latinos (HCHS/SOL) was performed as a collaborative study supported by contracts from the National Heart, Lung, and Blood Institute (NHLBI) to the University of North Carolina (N01-HC65233), University of Miami (N01-HC65234), Albert Einstein College of Medicine (N01-HC65235), Northwestern University (N01-HC65236), and San Diego State University (N01-HC65237). The following Institutes/Centers/Offices contribute to the HCHS/SOL through a transfer of funds to the NHLBI: National Institute on Minority Health and Health Disparities, National Institute on Deafness and Other Communication Disorders, National Institute of Dental and Craniofacial Research, National Institute of Diabetes and Digestive and Kidney Diseases, National Institute of Neurological Disorders and Stroke, National Institutes of Health Institution-Office of Dietary Supplements. This research was supported in part by an NHLBI supplement award to CRS. APG and MEN were supported in the research, analysis, and writing of this paper by the National Institute for Dental and Craniofacial Research and the Office of Behavioral and Social Sciences Research of the US National Institutes of Health for the project titled, Integrating Social and Systems Science Approaches to Promote Oral Health Equity (grant R01-DE023072) and by the National Center for Advancing Translational Sciences of the US National Institutes of Health for the project titled, Primary Care Screening by Dental Hygienists at Chairside: Developing and Evaluating an Electronic Tool (grant UL1TR000038). QQ received a Scientist Development Award (K01HL129892) from the National Heart, Lung and Blood Institute.

\section{Competing interests None declared.}

Ethics approval Yeshiva University Albert Einstein College of Medicine.

Provenance and peer review Not commissioned; externally peer reviewed.

Data sharing statement Data from HCHS/SOL can be accessed by submitting proposals for manuscripts or by submitting an ancillary study proposal through the HCHS/SOL website, https://http://www2.cscc.unc.edu/hchs/.

Open Access This is an Open Access article distributed in accordance with the Creative Commons Attribution Non Commercial (CC BY-NC 4.0) license, which permits others to distribute, remix, adapt, build upon this work noncommercially, and license their derivative works on different terms, provided the original work is properly cited and the use is non-commercial. See: http:// creativecommons.org/licenses/by-nc/4.0/

\section{REFERENCES}

1. Kochanek KD, Murphy SL, Xu J. Deaths: final data for 2011. Natl Vital Stat Rep 2015;63:1-120.

2. Lalla E, Cheng B, Kunzel C, et al. Dental findings and identification of undiagnosed hyperglycemia. J Dent Res 2013;92:888-92.

3. Facts for Features: Hispanic Heritage Month 2014: Sept. 15-Oct. 15 [article online], 2014. 2015. http://www.census.gov/newsroom/ facts-for-features/2014/cb14-ff22.html
4. Cowie CC, Rust KF, Byrd-Holt DD, et al. Prevalence of diabetes and high risk for diabetes using $\mathrm{A} 1 \mathrm{C}$ criteria in the U.S. population in 1988-2006. Diabetes Care 2010;33:562-8.

5. Menke A, Casagrande S, Geiss L, et al. Prevalence of and trends in diabetes among adults in the United States, 1988-2012. JAMA 2015;314:1021-9.

6. Schneiderman N, Llabre M, Cowie CC, et al. Prevalence of diabetes among Hispanics/Latinos from diverse backgrounds: the Hispanic Community Health Study/Study of Latinos (HCHS/SOL). Diabetes Care 2014;37:2233-9.

7. Patel MH, Kumar JV, Moss ME, et al. Diabetes and tooth loss: an analysis of data from the National Health and Nutrition Examination Survey, 2003-2004. J Am Dent Assoc 2013;144:478-85.

8. Kapp JM, Boren SA, Yun S, et al. Diabetes and tooth loss in a national sample of dentate adults reporting annual dental visits. Prev Chronic Dis 2007;4:A59.

9. Huang DL, Chan KC, Young BA, et al. Poor oral health and quality of life in older U.S. adults with diabetes mellitus. J Am Geriatr Soc 2013;61:1782-8.

10. Evert $A B$, Boucher JL, Cypress M, et al. Nutrition therapy recommendations for the management of adults with diabetes. Diabetes Care 2013;36:3821-42.

11. Demmer RT, Zuk AM, Rosenbaum M, et al. Prevalence of diagnosed and undiagnosed type 2 diabetes mellitus among US adolescents: results from the continuous NHANES, 1999-2010. Am J Epidemiol 2013;178:1106-13.

12. National Research Council. Hispanics and the future of America. Panel on Hispanics in the United States. In: Tienda M, Mitchell F, eds. Committee on population, division of behavioral and social sciences and education. Washington DC: The National Academies Press, 2006:412-24.

13. Northridge ME, Ue FV, Borrell LN, et al. Tooth loss and dental caries in community-dwelling older adults in northern Manhattan. Gerodontology 2012;29:e464-473.

14. Dye BA, Li X, Thorton-Evans G. Oral health disparities as determined by selected healthy people 2020 oral health objectives for the United States, 2009-2010. NCHS Data Brief 2012;4:1-8.

15. Sorlie PD, Aviles-Santa LM, Wassertheil-Smoller S, et al. Design and implementation of the Hispanic Community Health Study/Study of Latinos. Ann Epidemiol 2010;20:629-41.

16. Eklund SA, Pittman JL. Third-molar removal patterns in an insured population. J Am Dent Assoc 2001;132:469-75.

17. Gotfredsen K, Walls AW. What dentition assures oral function? Clin Oral Implants Res 2007;18(Suppl 3):34-45.

18. American Diabetes Association. Classification and diagnosis of diabetes. Sec 2. In: standards of medical care in diabetes-2016. Diabetes Care 2016;39(Suppl 1):S13-22.

19. Bull FC, Maslin TS, Armstrong T, et al. Global physical activity questionnaire (GPAQ): nine country reliability and validity study. $J$ Phys Act Health 2009;6:790-804.

20. U.S. Department of Health and Human Services. 2008 Physical activity guidelines for Americans. Washington DC, 2008. http:// health.gov/paguidelines/guidelines/

21. Guenther PM, Casavale KO, Reedy J, et al. Update of the Healthy Eating Index: HEl-2010. J Acad Nutr Diet 2013;113:569-80.

22. Schuller AA, Holst D. Oral status indicators DMFT and FS-T: reflections on index selection. Eur J Oral Sci 2001;109: $155-9$.

23. Eke PI, Page RC, Wei L, et al. Update of the case definitions for population-based surveillance of periodontitis. J Periodontol 2012;83:1449-54.

24. Du Clos TW. Function of C-reactive protein. Ann Med 2000;32:274-8.

25. Ridker PM. Clinical application of C-reactive protein for cardiovascular disease detection and prevention. Circulation 2003:107:363-9.

26. Beck JD, Youngblood M Jr, Atkinson JC, et al. The prevalence of caries and tooth loss among participants in the Hispanic Community Health Study/Study of Latinos. J Am Dent Assoc 2014; 145:531-40.

27. Lavange LM, Kalsbeek WD, Sorlie PD, et al. Sample design and cohort selection in the Hispanic Community Health Study/Study of Latinos. Ann Epidemiol 2010;20:642-9.

28. Demmer RT, Holtfreter B, Desvarieux M, et al. The influence of type 1 and type 2 diabetes on periodontal disease progression: prospective results from the Study of Health in Pomerania (SHIP). Diabetes Care 2012;35:2036-42.

29. Kaur G, Holtfreter B, Rathmann W, et al. Association between type 1 and type 2 diabetes with periodontal disease and tooth loss. $J$ Clin Periodontol 2009;36:765-74. 
30. Mugabo Y, Li L, Renier G, et al. The connection between C-reactive protein (CRP) and diabetic vasculopathy. Focus on preclinical findings. Curr Diabetes Rev 2010;6:27-34.

31. Lamster IB, Lalla E, Borgnakke WS, et al. The relationship between oral health and diabetes mellitus. J Am Dent Assoc 2008;139 (Suppl):19S-24S.

32. Taylor GW, Burt BA, Becker MP, et al. Severe periodontitis and risk for poor glycemic control in patients with non-insulin-dependent diabetes mellitus. J Periodontol 1996;67(10 Suppl):1085-93.

33. Furuta $M$, Ekuni $\mathrm{D}$, Irie $\mathrm{K}$, et al. Sex differences in gingivitis relate to interaction of oral health behaviors in young people. $J$ Periodontol 2011;82:558-65.

34. Blackwell DL, Lucas JW, Clarke TC, et al. Summary health statistics for U.S. adults: national health interview survey, 2012. Vital Health Stat 10 2014;260:1-161.
35. Willis A, Oxenham MF. The neolithic demographic transition and oral health: the Southeast Asian experience. Am J Phys Anthropol 2013;152:197-208.

36. Bonsall L. A comparison of female and male oral health in skeletal populations from late Roman Britain: implications for diet. Arch Oral Biol 2014;59:1279-300.

37. Daviglus ML, Talavera GA, Aviles-Santa ML, et al. Prevalence of major cardiovascular risk factors and cardiovascular diseases among Hispanic/Latino individuals of diverse backgrounds in the United States. JAMA 2012;308:1775-84.

38. Delgado JL, Johnson CL, Roy I, et al. Hispanic Health and Nutrition Examination Survey: methodological considerations. Am J Public Health 1990;80(Suppl):6-10.

39. Griffin SO, Jones JA, Brunson D, et al. Burden of oral disease among older adults and implications for public health priorities. $A m \mathrm{~J}$ Public Health 2012;102:411-18. 